\title{
Data challenges for future plant gene editing: expert opinion
}

\author{
Rim Lassoued $(\mathbb{D} \cdot$ Diego M. Macall $(\mathbb{D})$ Stuart J. Smyth $(\mathbb{D} \cdot$ Peter W. B. Phillips • \\ Hayley Hesseln $(\mathbb{D}$
}

Received: 18 January 2021 / Accepted: 31 May 2021 / Published online: 9 June 2021

(C) The Author(s) 2021

\begin{abstract}
Agricultural data in its multiple forms are ubiquitous. With progress in crop and input monitoring systems and price reductions over the past decade, data are now being captured at an unprecedented rate. Once compiled, organized and analyzed, these data are capable of providing valuable insights into much of the agri-food supply chain. While much of the focus is on precision farming, agricultural data applications coupled with gene editing tools hold the potential to enhance crop performance and global food security. Yet, digitization of agriculture is a double-edged sword as it comes with inherent security and privacy quandaries. Infrastructure, policies, and practices to
\end{abstract}

R. Lassoued $(\varangle) \cdot$ D. M. Macall ·

S. J. Smyth · H. Hesseln

Department of Agricultural and Resource Economics,

University of Saskatchewan, 51 Campus Drive,

Saskatoon, SK S7N 5A8, Canada

e-mail: rim.lassoued@usask.ca

D. M. Macall

e-mail: diego.macall@usask.ca

S. J. Smyth

e-mail: stuart.smyth@usask.ca

H. Hesseln

e-mail: hayley.hesseln@usask.ca

P. W. B. Phillips

The Johnson Shoyama Graduate School of Public Policy, University of Saskatchewan, 101 Diefenbaker Place,

Saskatoon, SK S7N 5B8, Canada

e-mail: peter.phillips@usask.ca better harness the value of data are still lacking. This article reports expert opinions about the potential challenges regarding the use of data relevant to the development and approval of new crop traits as well as mechanisms employed to manage and protect data. While data could be of great value, issues of intellectual property and accessibility surround many of its forms. The key finding of this research is that surveyed experts optimistically report that by 2030, the synergy of computing power and genome editing could have profound effects on the global agri-food system, but that the European Union may not participate fully in this transformation.

Keywords Big data - Data management $\cdot$ Food security · Harmonization · Innovation · Privacy

\section{Introduction}

Agriculture has steadily adopted a plethora of technological innovations, which are needed now more than ever if global food security issues are to be adequately addressed. Correlated with the revolution in data generation, novel plant breeding is paving the way for new opportunities in crop genetic improvement on a wide-scale and at a lower cost. A new breeding technology increasingly being used, gene editing-spearheaded by clustered regularly 
interspaced short palindromic repeats (CRISPR/ Cas)—is optimistically expected by the research community to enhance global agricultural productivity (Zhu et al. 2020; Lassoued et al. 2018a; Kim and Kim 2019). Experts have already expressed opinions about its benefits (Lassoued et al. 2019a; Qaim 2020; Eshed and Lippman 2019), its risks (Lassoued et al. 2019b; Zhao and Wolt 2017), and how it should be regulated (Lassoued et al. 2020; Whelan and Lema 2019; Eriksson et al. 2019; Wolt et al. 2016; Wolt and Wolf 2018; Fritsch 2019; Gatica-Arias 2020; Smyth 2019a, b; Cavaliere et al. 2019). High-throughput technologies are generating massive heterogeneous data at each stage of the breeding pipeline. Integration, manipulation and interpretation of large volumes of data are increasingly becoming automated and digitized in research and on the farm. Generation of scientific knowledge is profoundly and rapidly changing. Hypothesis-driven research is shifting to datadriven research where new plant genomes can be sequenced and annotated in a matter of days and some farmers are able to generate gigabytes of new data with each field they cultivate (Stevens 2013). The main challenge facing modern plant breeding programs is how to integrate these large volumes of genomic, phenotypic and environmental data to inform variety development decisions (Kuriakose et al. 2020; Zhao et al. 2019). The increased complexity and volume of breeding data make sophisticated analytical tools, new storage systems, and data management facilities for information integration a vital requirement in the agriculture industry (Heckenberger et al. 2008; Kuriakose et al. 2020).

As these tools become more useable, the research community will need to access them to effectively advance science and bridge the gap between laboratory discovery and field applications. It has been shown that open data can empower research and drive agricultural innovation, which in turn helps address global societal and environmental challenges, and supports economic growth (GODAN 2016, 2018; Cowan et al. 2014). There is no denying that data become valuable when adhering to the FAIR principles $^{1}$ - findable, accessible, interoperable and reusable-with the intent to enhance the ability of machines to automatically find and use the data, in addition to

\footnotetext{
${ }_{1}^{1}$ https://www.go-fair.org/fair-principles/, https://www. force11.org/fairprinciples.
}

supporting its reuse by individuals (Wilkinson et al. 2016). Yet, decisions and consensus with respect to practical implementation of these principles have the potential to limit adoption; the absence of proper standardization policies can block effective data exchange and integration (Krajewski et al. 2015; Jeppesen et al. 2018).

This article reports on a survey of experts that investigated potential uses and issues regarding the data relevant to the development and approval of new crop traits and agriculture in general. Our findings contribute to the debate about the fundamental principles for data sharing and related practical implementations. The article provides an overview of the different types of data, underlying legal protection mechanisms and issues around data sharing that are present in the context of the agriculture industry.

\section{Data types in the agri-food industry}

The complex ecosystems in which agricultural production takes place needs to be better understood if agricultural productivity is to continue increasing. A better understanding of the dynamics can be obtained with modern monitoring instruments that continuously register changes in physical environmental parameters (Huang et al. 2018; Kamilaris et al. 2017). Agricultural ecosystems produce vast amounts of data that modern digital technologies can now register and measure. Mining, or finding patterns in, this vast amount of data can provide unique insights into how complex agricultural ecosystems function. In essence, agricultural production systems can be understood as, or reduced to, information flows.

As various types of data can be generated and captured from operating machines (sensor-equipped) or agricultural production processes themselves, related analytics are increasingly integrated in each stage of the agricultural value chain. Along with phenotypic and genomic data, modern plant breeding teams extensively use spatial data from mobile computing devices. Among the wide variety of data collected in modern plant breeding processes, we identify and define the following as the most significant:

- Farm metadata comprising management information (practices and technologies) such as seeding 
depth, cultivar, crop rotations, machinery diagnostics, time and motion, ${ }^{2}$ and the dates of tillage, planting, scouting, spraying, and input application.

- Genomic data related to the structure, function, evolution, mapping and editing of the genome (hereditary information in the form of DNA and RNA). Genotyping solutions have increased the efficiency of plant breeding in fields by enabling selection at the seedling stage before the trait of interest is expressed, yielding time, labor, space, and cost savings in bringing new varieties to the market (Kuriakose et al. 2020). Various environments and software packages with specialized features have been developed to digitize genomic data (Kuriakose et al. 2020).

- Phenotypic data related to the morphological and functional plant traits (growth, tolerance, resistance, architecture, physiology, yield, etc.) and the relationship between these functions plays a crucial role in selection decisions in plant breeding. Traditional phenotyping techniques along with available genetic information do not yield an indepth functional analysis between genotype and phenotype, an obstacle to understanding the genetic basis for complex agronomic traits and thus, to progress in molecular breeding research (Rahaman et al. 2015; Omari et al. 2020; Zhao et al. 2019). With novel imaging technologies, reliable, automated and high through-put phenotyping or phenomics emerged to accelerate the accuracy and speed of phenotypic data for modelling and prediction of plant growth and structural development (Haque et al. 2018). Relative to genomics, digital phenotyping occurs at a slower pace as plant breeders are unsure on how voluminous and diverse phenotypic data can be usefully incorporated in breeding programs (Zhao et al. 2019; Awada et al. 2018; Kuriakose et al. 2020). Artificial intelligence tools are required to advance image-based phenotyping (Zhao et al. 2019). Current phenotypic data collection protocols remain largely fragmented and there is no standard way with which to store phenotypic both at the regional and the global levels, which is a challenge for data sharing (Zhao et al. 2019).

\footnotetext{
${ }^{2}$ Refers to amount of time machinery has devoted to a task. If the machine moves, within-the-farm sensors indicate the paths taken.
}

- Logistics data report on the transportation and storage of goods from the point of origin (farm) to the point of consumption (table). These data enable the traceability of product ingredients (Jin et al. 2017). The goal of logistics data is to meet endusers' traceability and/or source of origin requirements in a timely and cost-effective manner (block chain distributed ledgers can capture and report progress through the supply system). Consumers are able to trace the origins and processing of products and make purchasing decisions based on this information.

- Geospatial data refer to the locational, attribute and temporal information about objects, events, or phenomena that have a location on the surface of the earth (Stock and Guesgen 2016). In agriculture, geospatial data are the site-specific data usually associated with precision agriculture (e.g. sitespecific soil characteristics, inputs and yield) (Coble et al. 2016). Jeppesen et al. (2018) have implemented open geospatial infrastructure for data management and analytics and showed how it enables interoperability of precision agricultural data that can be shared in standardized formats, visualized online at a low cost for both developers and consumers of the data.

- Telematics data are collected from machines and can be measured and viewed remotely using sensors, positioning systems and telecommunication technologies. Telematics data refers to data on the field equipment and machinery operating certain tasks. As telematics involve wireless data transfer, efficient utilization is contingent on a reliable wireless internet connectivity (Mark and Griffin 2016).

- Consumption data refer to all information that pertains to consumption trends, such as tastes, packaging preferences, product labeling, appropriate presentation sizes, etc.

Massive high-dimensional data are being acquired from a gamut of sources throughout the multistage breeding process at low cost and in minimal time. Though reducing agricultural production systems and plants to their underlying information is a profound paradigm shift, this does not exempt this information from issues of access, intellectual property and privacy (Marden 2018; Smyth et al. 2020). The rise of digital networks expands data sharing and the risks of 
security breaches and misuse of sensitive or confidential data.

\section{Data sharing}

Legal protection mechanisms

The explosion of readily available data has yielded numerous benefits, including advancing research and speeding up innovation (by significantly reducing repetitive work), promoting scientific transparency and reproducibility, and stimulating new forms of collaborative knowledge production (e.g. citizen science, crowdsourcing) (Doldirina et al. 2018; Janssen et al. 2017). For instance, the Consultative Group on International Agricultural Research (CGIAR) is using crowed-sourced farmer knowledge to drive its Climate Change and Food Security (CGAFS) project (Bronson 2019). Public benefit, professional gain (scientific merit, partnership, etc.) and reproducible science were found to be the main motives for experts to share data. Despite these promises, the culture of data sharing remains fragile in domains where security and regulatory issues are prevalent. Privacy and transparency compete-sharing requires careful specification as unprotected disclosure can be risky. Data producers and owners use various measures to ensure lawful access to protect intellectual property assets. The most common of these legally-binding mechanisms are defined here.

- Free accessibility Governments around the globe are increasingly sharing publicly funded data on web portals and platforms free of charge, without restrictions on its usage or distribution, and in machine-readable formats, such as through the open government data movement (Zhenbin et al. 2020; OECD 2019). This is similar to open-source software development, where the code for software is publicly accessible and free to download. The only requirement with open-source development is that any specific improvements must be uploaded to the open-source sharing platform.

- Contracts traditional legal contracts (paper-based) define the rules and penalties in an agreement between two parties and, require central authority or external enforcement system (Brousseau and Glachant 2002, p. 3). Different parties (farmers, the cloud service providers, the networking service providers, etc.) are involved in contracts that include privacy, security and intellectual property protection clauses that need to be carefully negotiated to identify rights and obligations (Gupta et al. 2020). One recent innovation is computerized or smart contracts, which Szabo (1996) defines as "a set of promises, specified in digital form, including protocols within which the parties perform on these promises". Smart contracts are being used to manage data and service sharing among users without third party involvement (Sultana et al. 2020). As self-executing tools, they could also be used to automate regulatory activities (e.g. reporting and monitoring of required data, checking for compliance and fining for noncompliance, and recording decisions by a regulator) (Magazzeni et al. 2017).

- Intellectual property rights (IPRs) are laws that establish a regime for access, use or reuse of data, metadata, or data products and include patents (exclusive rights in invention), trademarks (brand protection), copyrights (authorship/ownership protection), and trade secrets (proprietary or confidential information protection) (Doldirina et al. 2018). IPRs yield exclusive rights to the creators or inventors which encourages them to share information and data without fear of intellectual theft.

- Encryption refers to the use of cryptography techniques to transform a plain text database into a (partially) encrypted database, thus making it unreadable to anyone except those who possess the knowledge of the encryption key(s). ${ }^{3}$ This allows users to securely share data over an insecure network or storage site (Boneh et al. 2011, p. 253).

- Commons refers to institutions that manage access to shared resources under certain restrictions. Creative Commons (CC) ${ }^{4}$ is a US-based non-profit organization that offers a suite of licenses defining standard options for the distribution and re-use of creative, copyrighted works (Hagedorn et al. 2011). Being the most widely common-used licenses, $\mathrm{CC}$ are in use throughout the globe and supported by IPRs laws (Doldirina et al. 2018). CC

\footnotetext{
3 https://link.springer.com/referenceworkentry/10.1007\% 2F978-1-4419-5906-5_677.

${ }^{4}$ https://creativecommons.org/.
} 
licenses are commonly used to provide open access for the publication of journal articles.

While these protection mechanisms are globally adopted, requirements, scope and implementation vary among nations and jurisdictions, and dispute settlement (via litigation or other action) is complicated and far from certain (Doldirina et al. 2018). The management of data sharing remains limited in practice (Feasey and de Streel 2020). Scholars assert that unsynchronized principles - technical and legalof data sharing and protection impede the interoperability of data and slow innovations in plant breeding.

\section{Governance of data sharing}

As advanced earlier, data integration (e.g. linking genotypic and phenotypic information) presents one of the main-if not the greatest-challenges facing modern plant breeding community, both in academia and industry. Standardization of big data annotation and access is a solution (Kuriakose et al. 2020; Coppens et al. 2017). Taking the example of phenotyping, Coppens (Coppens et al. 2017, p. 62) posits that: " $[\mathrm{t}]$ he future of plant phenotyping lies in synergism, as the comprehensive integration and analysis of this 'Big Data' allow to unravel the biological processes governing plant growth and development, and to advance plant breeding for muchneeded climate-resilient and high-yielding crops". Similarly, Kuriakose et al. (2020) assert that the success of modern plant breeding depends on standardized data management to ensure harmonization of multidimensional data (like genomics, phenotypic, and environment).

In addition to technical data standardization (e.g. data description, formats, platforms), harmonization of processes and rules for data access and application of novel biotechnologies are also critical for crop improvement. The international scientific community is working through the CGIAR centres and DivSeek International Network (DIN) to develop some of these structures. Nationally, greater congruence between regulatory approaches to gene editing are expected to advance plant breeding research, enable trade, and offer novel products to consumers.

\section{Method}

The data for this article stem from an online survey conducted between March and September of 2020. The survey was designed to gather expert opinions about the importance of different types of data in the agri-food industry and the legal mechanisms used to protect and manage use. The instrument also explored how countries might learn from each other when it comes to the approval of plant gene editing. The survey was emailed to a panel of 450 international scientists, government officials, and agribusiness professionals involved in plant biotechnology. ${ }^{5}$

This survey concludes a multi-year survey project piloted by a research team at the University of Saskatchewan between 2015 and 2020. The project investigated expert opinions regarding the application of new plant breeding techniques as a way to aid in the pursuit of global food security. Earlier surveys studied the regulatory and social barriers pertaining to novel breeding approaches using gene editing and related risks and potential benefits (Lassoued et al. 2018b, 2019a, b, 2020). As plant breeding has become data intensive, scientists are increasingly working on databases rather than cells. As part of our investigation, we explored (here and in a previous survey) how big data and related applications contribute to agricultural research productivity in ways that might enhance food security. This survey builds on a previous survey that explored how big data are currently used, benefits expected in the medium term, issues likely to arise in the data-sharing process, and impacts artificial intelligence could have on agriculture. This last survey of the project draws inferences on the enabling and disrupting impacts of technological innovations associated with big data.

Our study was deemed exempt from full ethics review by the Behavioural Ethics Board at the University of Saskatchewan on January 28, 2020 on the basis that the participants, as experts, were not themselves the focus of the research (BEH 97). ${ }^{6}$

\footnotetext{
5 The surveyed expert panel was obtained from a contact database that was created using the emails of participants, of several conferences on biotechnology organized by the lead researchers over the past couples of decades, as well as of experts from online searches.

${ }^{6}$ Per the Tri-Council Policy Statement: Ethical Conduct for Research Involving Humans, December 2014, Exemption Article 2.1.
} 
Nevertheless, our survey presented participants with a standard consent statement describing the study, identifying the absence of known risks associated with participation, and a reminder that participation was voluntary and responses would be anonymous and confidential. Upon expression of consent, participants were presented with the questionnaire (provided in the Appendix). ${ }^{7}$

\section{Results and analysis}

The survey was completed by 83 participants, resulting in a response rate of $18.5 \%$. Respondents are predominantly males (75\%), aged between 45 and 65 . Forty-three percent of the participants reside in North America (NA), 31\% in Europe, and 26\% are from the rest of the world (5\% in Africa, 5\% in Asia, 9\% in Oceania and 7\% in Central and South Americas). Thirty-four percent work in industry or for a private research institution, $26 \%$ for an academic institution, and $28 \%$ for government or in a public research institution. Sixty-three percent identified themselves as scientific experts, and $24 \%$ as social experts (lawyers, agribusiness professionals, etc.).

\section{Data governance}

Participants were asked to rank different types of data for their expected impact on enhancing food security. As illustrated in Table 1, genomic data (47\%), farmer metadata $(47 \%)$ and phenotypic data $(44 \%)$ were highly rated by respondents. While tied with farmer metadata, genomic data received the highest number of first choice responses. Data Bridge Market Research forecasts the plant genomics market is projected to reach US $\$ 11.7$ billion by 2025 , a growth rate of $8.3 \%$ per annum. ${ }^{8}$

\footnotetext{
$\overline{7}$ Only questions for which results are reported in this analysis are shared in the appendix. As this survey concludes the multiyear survey project, questions that report on previous surveys and the whole project were not shared here as they are out of the scope of this article.

${ }^{8}$ https://www.databridgemarketresearch.com/reports/global-plantgenomics-market; https://www.globenewswire.com/news-release/ 2019/09/18/1917201/0/en/Global-Plant-Genomics-MarketAnalysis-by-Objective-Type-Trait-Application-and-RegionForecast-2025.html.
}

Experts were asked which type(s) of data raise the most security or privacy concerns for them. Table 2 identifies that farmer metadata followed by consumption and genomics data are considered the most critical data types, identified by $37 \%, 27 \%$ and $25 \%$ of surveyed experts respectively. Big data governance including data ownership, privacy and security were identified as key requirements for reliable modern farm management (aka smart farming) (Gupta et al. 2020; Wolfert et al. 2017). Leakages of data produced from the mix of sensors, devices and farm equipment through unlawful access were judged to pose some threats. For example, Gupta et al. (2020 p. 34,569) identify that "leakage of agriculture anti-jamming devices information can help an attacker bypass these security measures, while leakage of soil, crop, and agriculture purchase information can cause severe economic losses to farmers, if such information is used by competitors or hostile actors".

Open versus closed data management mechanisms

Most surveyed experts opined that consumption data (80\%), followed by phenotyping data (69\%), geospatial data (64\%), genomics data $(61 \%)$ and logistics data $(58 \%)$ should be open and freely available to users (Table 3). As for farmer metadata and telematics data, experts had a diversity of opinions: some think that those data should be open, others think they should have restricted access, about one-quarter are uncertain.

The cross tabulation- a joint frequency distribution of cases based on two or more categorical variables that can be analyzed with the Chi-square statistic $\left(\chi_{(\mathrm{df}=\mathrm{k})}^{2}\right.$ with $\mathrm{k}$ degrees of freedom) - is used to determine whether the variables are statistically independent or are associated. Regardless of their workplace (private, academic or government), there was no statistically significant results ( $p$-value $>0.05$ ) in expert opinion regarding the openness of all types of data.

We also probed respondents about the impacts of open data. Open data are expected to generate a panoply of positive impacts on research transparency, food safety, pest management, and collaboration while there was concern about the impact on breeders' revenue, in particular (Table 4). For the different impacts listed in Table 4, expert opinion on the impact 
Table 1 Expert ranking of types of data by their importance to food security (\% responses)

\begin{tabular}{ll}
\hline Types of data & $\begin{array}{l}\text { Score } \\
(\%)^{\mathrm{a}}\end{array}$ \\
\hline Genomics data & 47 \\
Farmer metadata & 47 \\
Phenotypic data & 44 \\
Logistics data (farm to table) & 39 \\
Geospatial data (soil and yield) & 38 \\
Consumption data & 37 \\
Telematics data (farming machinery diagnostics, & 28 \\
time and motion) & \\
\hline
\end{tabular}

${ }^{\mathrm{a}}$ The score is a weighted sum value (\%) of the 7 ranked responses where $1 \mathrm{st}, 2 \mathrm{nd}, 3 \mathrm{rd}, 4 \mathrm{th}, 5 \mathrm{th}$, 6th and 7 th choices were weighted $0.7,0.6,0.5,0.4,0.3,0.2$ and 0.1 , respectively

Table 2 Expert opinion regarding data security concerns (\% responses)

\begin{tabular}{ll}
\hline Types of data & $\begin{array}{l}\text { Score } \\
(\%)^{\mathrm{a}}\end{array}$ \\
\hline $\begin{array}{l}\text { Farmer metadata (geospatial soil/yield data linked } \\
\text { to input used) }\end{array}$ & 37 \\
Consumption data & 27 \\
Genomics data & 25 \\
Logistics data (farm to table) & 21 \\
Telematics data (farming machinery diagnostics, & 19 \\
time and motion) & 16 \\
Phenotypic data & 12 \\
Geospatial data (soil and yield) & \\
\hline
\end{tabular}

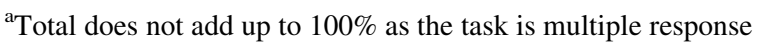

of open data was not associated with the nature of their workplace ( $\mathrm{p}$-value $>0.05$ ).

Our respondents reported they or their organizations use a mix of data management mechanisms, including contracts (51\%), free accessibility (49\%), copyrights (40\%) and trade secrets (40\%). Private research institutions are much more likely to use contracts $(60 \%)$ compared with academic institutions (23\%) and public research institutions (17\%). The Creative Commons is used by a minority of respondents. While the majority of respondents thought most data should be open access (Table 3), only 38\% of private researchers, $32 \%$ of academics and $30 \%$ of public research institutions offered free accessibility to others. In their place, they used copyrights $(47 \%$, $28 \%$ and $25 \%$ respectively) and trade secrets (59\%, $25 \%$ and $15 \%$ respectively). Encryption is also used and respondents suggested they are considering using it more. Interestingly, at least one-quarter of the sample are not knowledgeable about the mechanisms used in their work environments, which generates potential risk of researchers not conforming to a practice out of ignorance (Table 5).

\section{Data sharing}

The vast majority of surveyed experts indicated that they, or their organization, would share their own created data with regulators $(73 \%)$, international $(69 \%)$ and national (62\%) seed banks, public university breeders $(69 \%)$, research organizations $(67 \%)$ and online data repositories (58\%) (Table 6). Access to and data sharing of research data have been encouraged by research institutions, journals and funding agencies, some of which adopted open access data policies (digital, online, free of charge, and free of most copyright and licensing restrictions) to encourage
Table 3 Expert opinion on data openness (\% responses)

$\mathrm{P}, \mathrm{A}$ and $\mathrm{G}$ refer to the private, academic and government institutions

\begin{tabular}{|c|c|c|c|c|c|c|c|c|c|c|c|c|c|}
\hline \multirow[t]{2}{*}{ Data type } & \multicolumn{4}{|c|}{ Should be open } & \multicolumn{4}{|c|}{ Should be closed } & \multicolumn{4}{|c|}{ Do not know } & \multirow{2}{*}{$\begin{array}{l}\chi_{(\mathrm{df}=4)}^{2} \\
\mathrm{p} \text {-value }\end{array}$} \\
\hline & $\mathrm{P}$ & A & G & Total & $\mathrm{P}$ & A & $\mathrm{G}$ & Total & $\mathrm{P}$ & A & $\mathrm{G}$ & Total & \\
\hline Consumption & 33 & 20 & 27 & 80 & 4 & 4 & 4 & 12 & 4 & 4 & 0 & 8 & $4.088 ; 0.394$ \\
\hline Phenotyping & 25 & 20 & 24 & 69 & 15 & 4 & 5 & 24 & 1 & 4 & 2 & 7 & $6.444 ; 0.168$ \\
\hline Geospatial & 24 & 18 & 22 & 64 & 14 & 5 & 4 & 23 & 5 & 4 & 4 & 13 & $4.370 ; 0.358$ \\
\hline Genomics & 20 & 21 & 20 & 61 & 17 & 5 & 5 & 27 & 4 & 5 & 3 & 12 & $9.189 ; 0.057$ \\
\hline Logistics & 26 & 17 & 15 & 58 & 7 & 7 & 9 & 23 & 8 & 5 & 6 & 19 & $1.929 ; 0.749$ \\
\hline Metadata & 16 & 16 & 9 & 41 & 19 & 8 & 12 & 39 & 6 & 6 & 8 & 20 & $4.370 ; 0.358$ \\
\hline Telematics & 17 & 15 & 8 & 40 & 15 & 7 & 13 & 35 & 8 & 8 & 9 & 25 & $4.103 ; 0.392$ \\
\hline
\end{tabular}


Table 4 Expert opinion on the impact of open data (\% of responses)

\begin{tabular}{|c|c|c|c|c|}
\hline & Negative & No impact & Positive & Don't know \\
\hline Transparency in research systems & 1 & 13 & 81 & 5 \\
\hline Food safety concerns & 3 & 10 & 79 & 8 \\
\hline Pest management & 2 & 10 & 75 & 13 \\
\hline Collaboration $^{\mathrm{a}}$ & 10 & 9 & 70 & 11 \\
\hline Regulatory compliance & 8 & 12 & 70 & 10 \\
\hline Innovation in any aspect of the plant breeding process & 14 & 4 & 69 & 13 \\
\hline Claims about product quality & 10 & 10 & 69 & 11 \\
\hline Management of scarce natural resources & 6 & 16 & 65 & 13 \\
\hline Farmer profitability & 12 & 18 & 53 & 17 \\
\hline Direct cash costs associated with accessing data & 17 & 16 & 51 & 16 \\
\hline Indirect costs of data accessing data & 15 & 21 & 51 & 13 \\
\hline Breeder's revenue & 35 & 19 & 26 & 20 \\
\hline
\end{tabular}

${ }^{\mathrm{a} C}$ Collaboration between governments, businesses, non-governmental organizations (NGOs) and individuals

Table 5 Expert use of data management mechanisms in their work environment (\% responses)

\begin{tabular}{lllll}
\hline & Already using & Would consider using & Would not use & Don't know \\
\hline Contracts & 51 & 17 & 6 & 26 \\
Free accessibility & 49 & 16 & 8 & 27 \\
Copyrights & 40 & 16 & 17 & 27 \\
Trade secrets & 40 & 19 & 12 & 29 \\
Encryption & 30 & 27 & 7 & 36 \\
Creative commons licenses & 23 & 27 & 8 & 42 \\
\hline
\end{tabular}

researchers to deposit underlying data in a disciplinary or institutional repository (National Academy of Sciences 2009). However, data access policies are still immature. Research institutions and sponsors may need to come together to identify best practices and policy models (National Academy of Sciences et al. 2009). The exception to this sharing is that few of the respondents judged it likely that they would share data with supply chain integrators (30\%), farm implement manufacturers $(30 \%)$ or multinational seed companies (27\%).

One common perception is that increased data might complicate already difficult regulatory processes. To test that possibility, we asked our respondents whether they would be willing to share data created with regulators, finding that $73 \%$ of respondents were likely or very likely to do so regardless where they reside (p-value $>0.05)$. Indeed, the plurality of participants from North America (25\%), Europe (25\%), Oceania (7\%), Africa (5\%), Asia (5\%) and Central and South America (5\%) indicated that they have no issues to share data with regulators. Few if any of our respondents signaled much active concern with sharing, although about one third of respondents in North America hesitated to signal any clear intent.

The role of foreign evidence in approval of gene editing

Survey respondents were presented with the following scenario: "In another country with a similar regulatory system to your own, a gene-edited crop or product received approval. This approval was based on a 
Table 6 List of sources with whom experts share data (\% responses)

\begin{tabular}{|c|c|c|c|c|}
\hline & Unlikely & Neither & Likely & DNK \\
\hline Regulators & 4 & 5 & 73 & 18 \\
\hline International seed banks & 6 & 9 & 69 & 16 \\
\hline Public breeders at universities & 3 & 12 & 69 & 16 \\
\hline Consultative Group on International Agricultural Research Centres & 7 & 10 & 67 & 16 \\
\hline Agriculture research organizations, agencies and departments & 5 & 11 & 67 & 17 \\
\hline Environmental stewardship programs & 8 & 11 & 65 & 16 \\
\hline National seed banks (e.g. USDA) & 8 & 11 & 62 & 19 \\
\hline Online data repositories (e.g. genomics, phonemics websites) & 12 & 13 & 58 & 17 \\
\hline Global Open Data for Agriculture and Nutrition & 8 & 9 & 52 & 31 \\
\hline Small or entrepreneurial companies & 17 & 23 & 40 & 20 \\
\hline Supply chain integrators (e.g. Cargill) & 17 & 32 & 30 & 21 \\
\hline Implement firms (e.g. John Deere) & 19 & 27 & 30 & 24 \\
\hline Multinational seed companies (e.g. Bayer) & 29 & 28 & 27 & 16 \\
\hline
\end{tabular}

docket of evidence generated in that country (e.g. scientific experiments to support reviews for safety, efficacy and environmental sustainability)" and asked whether they believed their government would consider that same docket of evidence when applying for approval in their country. The responses (Table 7) show that $45 \%$ (including half of the North American and a third of the European participants) were optimistic that foreign data could satisfy domestic requirements, but decisions about approving a geneedited crop would be made domestically. Almost onequarter of the sample believed that data would be treated as supplemental and not sufficient for domestic requirements while $20 \%$ confirmed that data collection and analysis would need to be redone in their country. None of the experts expected that data and/or foreign decisions would satisfy domestic requirements. This result is not surprising given the heterogeneous regulatory systems and different environmental conditions across the world. Governments are unwilling to appear to be ceding regulatory authority to foreign governments or institutions. Over the last five years, a few countries in South America (esp. Argentina, Chile, Brazil and Colombia), North America (US and Canada), Australia and Japan have developed their own gene editing frameworks based on the risks of the resulting product rather than the process used to create it. The EU is a notable exception, as it treats gene editing as analogous to genetic engineering, and hence covered by de facto bans across the EU. Recently, many European research institutes and academies called for harmonization of the EU regulatory landscape, emphasizing that legislation on gene editing should consider the characteristics of the plant instead of the approaches used in its development (Dima et al. 2020).

When asked about how long it will take gene editing to have a significant impact on the agricultural sector, $88 \%$ assert that the impact will be seen in the global market (excluding the EU) within 10 years (Table 8). About half of the sample expect an impact will not be seen until later in the EU market.

\section{Conclusion}

Experts think that genomic and phenotypic data along with farm metadata are most likely to impact future global food security. However, experts acknowledge that privacy issues, particularly around farm metadata, cannot be dismissed and must be appropriately addressed. Especially given that in the near future, it can be possible for 'hackers' to gain access to proprietary farm data. Such data can be sold or used with ill intent and end up being pernicious to farmers or entire industries. For several stakeholders in the agri-food sector, big data present several challenges including storage, management, integration, security 
Table 7 Experts opinion on how their government would use foreign evidence (\% responses by region)

\begin{tabular}{|c|c|c|c|c|c|c|c|}
\hline $\begin{array}{l}\text { Would your government consider that same foreign docket of } \\
\text { evidence when approving gene-edited crop in your country? }\end{array}$ & Africa & Asia & Europe & $\begin{array}{l}\text { Central/ } \\
\text { South } \\
\text { America }\end{array}$ & $\begin{array}{l}\text { North } \\
\text { America }\end{array}$ & Oceania & Total \\
\hline $\begin{array}{l}\text { No, data collection and analysis would need to be redone in my } \\
\text { country }\end{array}$ & 2 & 2 & 10 & 2 & 4 & - & 20 \\
\hline $\begin{array}{l}\text { Yes, but data would be treated as supplemental and not } \\
\text { sufficient for domestic requirements }\end{array}$ & 2 & & 6 & 1 & 11 & 4 & 24 \\
\hline $\begin{array}{l}\text { Yes, foreign data could satisfy domestic requirements, but } \\
\text { decisions would be made domestically }\end{array}$ & 1 & 2 & 11 & 4 & 22 & 5 & 45 \\
\hline Don't know & - & 1 & 4 & - & 6 & - & 11 \\
\hline Total & 5 & 5 & 31 & 7 & 43 & 9 & 100 \\
\hline
\end{tabular}

Table 8 Expert opinion on the expected timeframe for gene editing to have a significant impact on the agricultural sector (\% responses)

\begin{tabular}{lllll}
\hline & $<5$ years & $5-10$ years & $10+$ years & Don't know \\
\hline In your country & 22 & 40 & 33 & 5 \\
In the global market excluding the EU & 30 & 58 & 11 & 1 \\
In the EU market & 6 & 22 & 49 & 23 \\
\hline
\end{tabular}

and confidentiality. In addition, proprietary integrations and non-standardized formats and connections have been slowing the adoption of novel agricultural technologies (Jeppesen et al. 2018).

If data are going to drive the future of agriculture and food production, clear and transparent rules and customs for the access and mining of data are needed. A majority of surveyed experts, whether working in a private or a public institution, think open science and data sharing are beneficial overall, however technical and legal solutions such as collaborative infrastructure and coherent protection services have yet to be generalized. Moreover, though most experts think consumption data should be freely available, this is the second lowest ranked type of data that are believed to contribute to future food security. This is not surprising given that the respondents of this survey are predominantly scientists. That is, they are considering only supply side food security, and not contemplating demand. Hence, scientists are more willing to share information, which is not directly linked to their research endeavors, rather, the information that guides them. We highlight that the results reported here are based on the opinions of a relatively small expert sample. Further studies focusing on these issues are important.

Acknowledgements This research was undertaken with funding from the Canada First Research Excellence Fund (CFREF) that established the Plant Phenotyping and Imaging Research Centre (P2IRC) project.

Authors' contributions Rim Lassoued: Conceptualization, Data Analysis, Drafting. Diego M. Macall: Conceptualization, Drafting. Stuart J. Smyth: Conceptualization, Drafting and Editing, Funding Acquisition. Peter W.B. Phillips: Conceptualization, Reviewing and Editing, Funding Acquisition. Hayley Hesseln: Conceptualization, Reviewing and Editing.

Funding This research was funded by the Canada First Research Excellence Fund (CFREF) that established the Plant Phenotyping and Imaging Research Centre (P2IRC) project.

Availability of data The raw data supporting the conclusions of this manuscript are not publicly available because academic survey policy at the University of Saskatchewan states that all survey data will be protected and held confidential to ensure responder anonymity. Requests to access these datasets should be directed to Dr. Stuart Smyth at stuart.smyth@usask.ca. 


\section{Declarations}

Conflict of interest The authors declare that they have no conflict of interest.

Ethical approval All procedures performed in this study involving human participants were in accordance with the ethical standards of the University of Saskatchewan.

Open Access This article is licensed under a Creative Commons Attribution 4.0 International License, which permits use, sharing, adaptation, distribution and reproduction in any medium or format, as long as you give appropriate credit to the original author(s) and the source, provide a link to the Creative Commons licence, and indicate if changes were made. The images or other third party material in this article are included in the article's Creative Commons licence, unless indicated otherwise in a credit line to the material. If material is not included in the article's Creative Commons licence and your intended use is not permitted by statutory regulation or exceeds the permitted use, you will need to obtain permission directly from the copyright holder. To view a copy of this licence, visit http://creativecommons.org/licenses/by/4.0/.

\section{Appendix: Questionnaire}

Dear Participant,

First, we would like to THANK YOU for your active participation in, and valuable inputs to, our multi-year survey project during which we have been collecting expert opinions on innovative technologies pertaining to plant breeding. Project output to date is available at https://research-groups. usask.ca/nbt-regulation/publications/articles.php.

We have shared a number of papers with those who requested them. If you wish to receive full papers, please email us at nbt.regulation@usask.ca.

Our project wraps up with the current invitation to participate in our eleventh and last survey. We would like to learn about your opinions pertaining to potential impact of digital agricultural knowledge on plant breeding regulations along with your overall views of our surveys.

Dr. Stuart Smyth (stuart.smyth@usask.ca, (306) 966-2929) and Dr. Peter Phillips (peter.phillips@usask.ca, (306) 966-4021) have been leading this project over the course of the last four years. They can be contacted should you have any questions or comments. Any questions regarding your rights as a participant may be addressed to the University of Saskatchewan Research Ethics Office ethics.office@usask.ca; (306) 966-2975. Out of town participants may call toll free (888) 966-2975.

This survey is hosted by Voxco, a Canadian-owned and managed company whose data is securely stored in Canada. Please consider printing this page for your records. There are no known risks to participating in this survey; however, as with any online activity the risk of breach of confidentiality is always possible.

In order to complete this survey, you may be required to answer certain questions; however, you are never obligated to respond and you may withdraw from the survey at any time by closing your internet browser.

By selecting next and completing this questionnaire, your free and informed consent is implied and indicates that you understand and accept the above conditions of participating in this study.

We are interested in your opinions about the potential uses and challenges around the use of data relevant to the development and approval of new crop traits and agriculture in general.

Q1. Which data do you think will have the biggest impact on enhancing food security?

Please rank the following type of data in order of importance with " 1 " being "data with the biggest impact" and "7" being "data with the least impact".

- Geospatial (soil and yield) data

- Farmer metadata (Geospatial soil/yield data linked to input used)

- Telematics data (Farming machinery diagnostics, time and motion)

- Genomics data

- Phenotyping data

- Consumption data

- Logistics data (farm to table)

Q2. Which types of data raises most security/privacy concerns for you? (Check all applicable)

- Geospatial (soil and yield) data 
- Farmer metadata (Geospatial soil/yield data linked to input used)

- Telematics data (Farming machinery diagnostics, time and motion)

- Genomics data

- Phenotyping data

- Consumption data

- Logistics data (farm to table)

Q3. For each type of data, please indicate whether you think it should be open (i.e., freely available to any user), or closed (i.e., restricted access):

\begin{tabular}{llll}
\hline Data types & Should be open & Should be closed \\
\hline
\end{tabular}

Geospatial (soil and yield) data

Farmer metadata (Geospatial soil/yield data linked to input used)

Telematics data (Farming machinery diagnostics, time and motion)

Genomics data

Phenotyping data

Consumption data

Logistics data (farm to table)

Q4. For data you have created, which data management mechanisms do you or your organization use or consider using in future?

\begin{tabular}{|c|c|c|c|c|}
\hline & Already using & Would consider using & Would not use & Don't know \\
\hline \multicolumn{5}{|l|}{ Copyright } \\
\hline \multicolumn{5}{|l|}{ Trade secret } \\
\hline \multicolumn{5}{|l|}{ Encryption } \\
\hline \multicolumn{5}{|l|}{ Free accessibility } \\
\hline \multicolumn{5}{|l|}{ Creative commons } \\
\hline \multicolumn{5}{|l|}{ Contracts } \\
\hline Other (please specify): & & & & \\
\hline
\end{tabular}

Q5. Data is considered open if anyone is free to use, reuse, and redistribute it-subject only, at most, to the requirements of attribution and sharing.

In your opinion, what impact would open data have on the following considerations?

\begin{tabular}{llll}
\hline Impacts on: & $\begin{array}{l}\text { Very } \\
\text { negative }\end{array}$ & Negative Neutral Positive $\begin{array}{l}\text { Very } \\
\text { positive }\end{array}$ & $\begin{array}{l}\text { Don't } \\
\text { know }\end{array}$ \\
\hline
\end{tabular}

Food safety concerns

Management of scarce natural resources

Pest management 


\begin{tabular}{llll}
\hline Impacts on: & $\begin{array}{l}\text { Very } \\
\text { negative }\end{array}$ & Negative Neutral Positive & $\begin{array}{l}\text { Very } \\
\text { positive }\end{array}$ \\
& $\begin{array}{l}\text { Don't } \\
\text { know }\end{array}$ \\
\hline
\end{tabular}

Transparency in research systems

Innovation in any aspect of the plant breeding process

Collaboration between governments, businesses, non-governmental organizations (NGOs) and individuals

Direct cash costs associated with accessing data

Indirect costs of data accessing data from others (i.e. time and resources

it takes to locate, request and negotiate data access)

Regulatory compliance

Claims about product quality

Farmer profitability

Breeder's revenue

Q6. Would you or your organization share any data you created with any of the following:

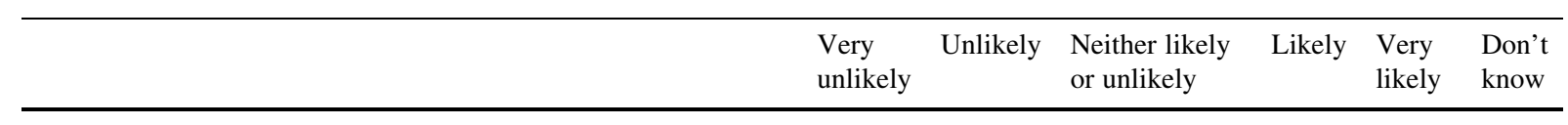

Global Open Data for Agriculture and Nutrition (https://www. godan.info)

Consultative Group on International Agricultural Research Centres

(https://www.cgiar.org)

National seed banks (e.g. USDA)

International seed banks (e.g. The International Maize and Wheat Improvement Center https://www.cimmyt.org)

National agriculture research organizations, agencies and departments in your countries or elsewhere

Multinational seed companies (e.g.Bayer)

Supply chain integrators (e.g. Cargill)

Online data repositories (e.g. genomics, phonemics websites)

Small or entrepreneurial companies

Public breeders at universities (e.g. University of Wageningen)

Environmental stewardship programs

Regulators (e.g. European Food Safety Authority: http://www.efsa. europa.eu)

Implement firms (e.g. John Deere)

Other (please specify):

Q7. Next, Please imagine the following scenario: 
In another country with a similar regulatory system to your own, a genome-edited crop or product received approval. This approval was based on a docket of evidence generated in that country (e.g. scientific experiments to support reviews for safety, efficacy and environmental sustainability).

Do you believe that the government in your country would consider that same docket of evidence when applying for approval in your own country?

- No, data collection and analysis would need to be redone in my country

- Yes, but data would be treated as supplemental and not sufficient for domestic requirements.

- Yes, foreign data could satisfy domestic requirements, but decisions would be made domestically.

- Yes, data and foreign decisions would satisfy domestic requirements

- Don't know

Q8. How many years do you think it will take for genome editing to have a significant impact on the agricultural sector?

\begin{tabular}{|c|c|c|c|c|}
\hline & $<5$ years & $5-10$ years & $\begin{array}{l}10+ \\
\text { years }\end{array}$ & $\begin{array}{l}\text { I don't } \\
\text { know }\end{array}$ \\
\hline \multicolumn{5}{|l|}{ In your country } \\
\hline \multicolumn{5}{|l|}{$\begin{array}{l}\text { In the global market } \\
\text { excluding the EU }\end{array}$} \\
\hline In the EU market & & & & \\
\hline
\end{tabular}

Finally, please tell us a bit about yourself ...

Q9. Do you identify yourself as:

- Male

- Female

- Other

- Prefer not to say

Q10. Where do you currently reside?

- Africa

- Asia

- Europe

- Central or South America

- North America
- Oceania

Q11. Do you identify yourself as:

- A life scientist (biologist, ecologist, etc.)

- A social scientist/Agri-business professional (economist, lawyer, manager etc.)

- Other (Please specify):

Q12. Do you mainly work for:

- Industry/private research institution

- Academic institution

- Government/Public research institution

- Other (Please specify):

Q13. Any additional comments about this survey?

\section{References}

Awada L, Phillips PWB, Smyth SJ (2018) The adoption of automated phenotyping by plant breeders. Euphytica 214(8):148. https://doi.org/10.1007/s10681-018-2226-z

Boneh D, Sahai A, Waters B (2011). Functional encryption: definitions and challenges. Berlin

Bronson K (2019) Digitization and big data in food security and sustainability. In: Ferranti P, Berry EM, Anderson JR (eds) Encyclopedia of food security and sustainability. Elsevier, Oxford, pp 582-587

Brousseau E, Glachant J-M (2002) The economics of contracts: theories and applications. Cambridge University Press, Cambridge

Cavaliere G, Devolder K, Giubilini A (2019) Regulating Genome Editing: For an Enlightened Democratic Governance. Camb Q Healthc Ethics 28(1):76-88. https://doi.org/10. 1017/S0963180118000403

Coble K, Griffin T, Ahearn M, Ferrell S, McFadden J, Sonka S, Fulton J (2016) Advancing U.S. agricultural competitiveness with big data and agricultural economic market information, analysis, and research. http://ageconsearch. umn.edu/record/249847/files/10-10-2016BigAgData.pdf

Coppens F, Wuyts N, Inzé D, Dhondt S (2017) Unlocking the potential of plant phenotyping data through integration and data-driven approaches. Curr Opin Syst Biol 4:58-63. https://doi.org/10.1016/j.coisb.2017.07.002

Cowan D, Alencar P, McGarry F (2014). Perspectives on open data: issues and opportunties. Paper presented at the 2014 IEEE international conference on software science, technology and engineering

Dima O, Bocken H, Custers R, Inze D, Puigdomenech P (2020) Genome editing for crop improvement. Berlin 
Doldirina C, Eisenstadt A, Onsrud H, Uhlir P (2018) Legal approaches for open access to research data. https://doi. org/10.31228/osf.io/n7gfa

Eriksson D, Kershen D, Nepomuceno A, Pogson BJ, Prieto H, Purnhagen K, Whelan A (2019) A comparison of the EU regulatory approach to directed mutagenesis with that of other jurisdictions, consequences for international trade and potential steps forward. New Phytol 222(4):1673-1684. https://doi.org/10.1111/nph.15627

Eshed Y, Lippman ZB (2019) Revolutions in agriculture chart a course for targeted breeding of old and new crops. Science 366(6466):eaax0025. https://doi.org/10.1126/science. aax0025

Feasey R, de Streel A (2020). Data sharing for digital markets contestability: towards a governance framework: centre on regulation in Europe asbl (CERRE)

Fritsch J (2019) Towards a scientifically justified, differentiated regulation of genome edited plants in the EU (2019) Statement Retrieved from Halle (Saale) Germany

Gatica-Arias A (2020) The regulatory current status of plant breeding technologies in some Latin American and the Caribbean countries. Plant Cell Tissue Organ Cult (PCTOC) 141(2):229-242. https://doi.org/10.1007/ s11240-020-01799-1

GODAN (2016) A global data ecosystem for agriculture and Food. https://www.godan.info/sites/default/files/ documents/Godan_Global_Data_Ecosystem_Publication_ lowres.pdf. Accessed 29 Oct 2020

GODAN (2018) GODAN's impacts 2014 to 2018-improving agriculture, food and nutrition with open data. https:// www.godan.info/sites/default/files/GODAN\%27s\% 20Impacts $\% 202014 \% 202020$ to $\% 202018 \% 202020-\%$ 202020Improving\%202020Agriculture $\% 202012 \mathrm{C} \%$ 202020Food\%202020and\%202020Nutrition\% 202020with\%202020Open\%202020Data\%202020_ 202010.pdf. Accessed 202010/202029/202020

Gupta M, Abdelsalam M, Khorsandroo S, Mittal S (2020) Security and privacy in smart farming: challenges and opportunities. IEEE Access 8:34564-34584. https://doi. org/10.1109/ACCESS.2020.2975142

Hagedorn G, Mietchen D, Morris RA, Agosti D, Penev L, Berendsohn WG, Hobern D (2011) Creative commons licenses and the non-commercial condition: implications for the re-use of biodiversity information. ZooKeys 150:127-149. https://doi.org/10.3897/zookeys.150.2189

Haque E, Taniguchi H, Hassan MM, Bhowmik P, Karim MR, Śmiech M, Islam T (2018) Application of CRISPR/Cas9 genome editing technology for the improvement of crops cultivated in tropical climates: recent progress, prospects, and challenges. Front Plant Sci. https://doi.org/10.3389/ fpls.2018.00617

Heckenberger M, Maurer HP, Melchinger AE, Frisch M (2008) The Plabsoft database: a comprehensive database management system for integrating phenotypic and genomic data in academic and commercial plant breeding programs. Euphytica 161(1):173-179. https://doi.org/10.1007/ s10681-007-9478-3

Huang Y, Chen Z-x, Yu T, Huang X-z, Gu X-f (2018) Agricultural remote sensing big data: management and applications. J Integr Agric 17(9):1915-1931. https://doi.org/ $10.1016 /$ S2095-3119(17)61859-8
Janssen M, Konopnicki D, Snowdon JL, Ojo A (2017) Driving public sector innovation using big and open linked data (BOLD). Inf Syst Front 19(2):189-195. https://doi.org/10. 1007/s10796-017-9746-2

Jeppesen JH, Ebeid E, Jacobsen RH, Toftegaard TS (2018) Open geospatial infrastructure for data management and analytics in interdisciplinary research. Comput Electron Agric 145:130-141. https://doi.org/10.1016/j.compag. 2017.12.026

Jin S, Zhang Y, Xu Y (2017) Amount of information and the willingness of consumers to pay for food traceability in China. Food Control 77:163-170

Kamilaris A, Kartakoullis A, Prenafeta-Boldú FX (2017) A review on the practice of big data analysis in agriculture. Comput Electron Agric 143:23-37. https://doi.org/10. 1016/j.compag.2017.09.037

Kim J-I, Kim J-Y (2019) New era of precision plant breeding using genome editing. Plant Biotechnol Rep 13(5):419-421. https://doi.org/10.1007/s11816-01900581-w

Krajewski P, Chen D, Ćwiek H, van Dijk ADJ, Fiorani F, Kersey P, Weise S (2015) Towards recommendations for metadata and data handling in plant phenotyping. J Exp Bot 66(18):5417-5427. https://doi.org/10.1093/jxb/erv271

Kuriakose SV, Pushker R, Hyde EM (2020) Data-driven decisions for accelerated plant breeding. In: Gosal SS, Wani SH (eds) Accelerated plant breeding, volume 1: Cereal crops. Springer, Cham, pp 89-119

Lassoued R, Hesseln H, Phillips PWB, Smyth SJ (2018a) Top plant breeding techniques for improving food security: an expert Delphi survey of the opportunities and challenges. Int J Agric Resour Gov Ecol. https://doi.org/10.1504/ IJARGE.2018.097986

Lassoued R, Macall DM, Hesseln H, Phillips PW, Smyth SJ (2019a) Benefits of genome-edited crops: expert opinion. Transgenic Res 28(2):247-256

Lassoued R, Macall DM, Smyth SJ, Phillips PW, Hesseln H (2019b) Risk and safety considerations of genome edited crops: expert opinion. Curr Res Biotechnol 1:11-21

Lassoued R, Macall DM, Smyth SJ, Phillips PW, Hesseln H (2020) How should we regulate products of new breeding techniques? Opinion of surveyed experts in plant biotechnology. Biotechnol Rep e00460

Lassoued R, Smyth SJ, Phillips PWB, Hesseln H (2018b) Regulatory uncertainty around new breeding techniques. Front Plant Sci. https://doi.org/10.3389/fpls.2018.01291

Magazzeni D, McBurney P, Nash W (2017) Validation and verification of smart contracts: a research agenda. Computer 50(9):50-57. https://doi.org/10.1109/MC.2017. 3571045

Marden E (2018) International agreements may impact genomic technologies. Nat Plants 4(1):2-4. https://doi.org/10.1038/ s41477-017-0087-4

Mark T, Griffin T (2016). Defining the barriers to telematics for precision agriculture: connectivity supply and demand. Paper presented at the 169. http://ageconsearch.umn.edu/ record/230090/files/Paper169.pdf

National Academy of Sciences, National Academy of Engineering, Institute of Medicine (2009) Ensuring the integrity, accessibility, and stewardship of research data in the 
digital age. The National Academies Press, Washington, DC

OECD (2019) Data accessibility: open, free and accessible formats

Omari M, Lee J, Faqeerzada MA, Park E, Cho B-K (2020) Digital image-based plant phenotyping: a review. Korean $\mathrm{J}$ Agric Sci 47(1):119-130. https://doi.org/10.7744/kjoas. 20200004

Qaim M (2020) Role of new plant breeding technologies for food security and sustainable agricultural development. Appl Econ Perspect Policy 42(2):129-150. https://doi.org/ 10.1002/aepp.13044

Rahaman MM, Chen D, Gillani Z, Klukas C, Chen M (2015) Advanced phenotyping and phenotype data analysis for the study of plant growth and development. Front Plant Sci 6:619-619. https://doi.org/10.3389/fpls.2015.00619

Smyth SJ (2019a) Global status of the regulation of genome editing technologies. CAB Rev 14(21):1-6. https://doi.org/ 10.1079/PAVSNNR201914021

Smyth SJ (2019b) Regulation of genome editing in plant biotechnology: Canada. In: Dederer H-G, Hamburger D (eds) Regulation of genome editing in plant biotechnology: a comparative analysis of regulatory frameworks of selected countries and the EU. Springer, Cham, pp 111-135

Smyth SJ, Macall DM, Phillips PW, de Beer J (2020) Implications of biological information digitization: access and benefit sharing of plant genetic resources. J World Intellect Prop

Stevens H (2013). Life out of sequence: a data-driven history of bioinformatics.

Stock K, Guesgen H (2016) Chapter 10-geospatial reasoning with open data. In: Layton R, Watters PA (eds) Automating open source intelligence. Syngress, Boston, pp 171-204

Sultana TA, Almogren A, Akbar M, Zuair M, Ullah I, Javaid N (2020) Data sharing system integrating access control mechanism using blockchain-based smart contracts for IoT devices. Appl Sci 10:488

Szabo N (1996) Smart contracts: building blocks for digital markets.
Whelan A, Lema M (2019) Regulation of genome editing in plant biotechnology: Argentina. In: Dederer H, Hamburger D (eds) Regulation of genome editing in plant biotechnology. Springer, Cham

Wilkinson MD, Dumontier M, Aalbersberg IJ, Appleton G, Axton M, Baak A, Mons B (2016) The FAIR guiding principles for scientific data management and stewardship. Sci Data 3(1):160018. https://doi.org/10.1038/sdata.2016. 18

Wolfert S, Ge L, Verdouw C, Bogaardt M-J (2017) Big data in smart farming-a review. Agric Syst 153:69-80. https:// doi.org/10.1016/j.agsy.2017.01.023

Wolt JD, Wang K, Yang B (2016) The regulatory status of genome-edited crops. Plant Biotechnol J 14(2):510-518. https://doi.org/10.1111/pbi.12444

Wolt JD, Wolf C (2018) Policy and governance perspectives for regulation of genome edited crops in the United States. Front Plant Sci. https://doi.org/10.3389/fpls.2018.01606

Zhao C, Zhang Y, Du J, Guo X, Wen W, Gu S, Fan J (2019) Crop phenomics: current status and perspectives. Front Plant Sci. https://doi.org/10.3389/fpls.2019.00714

Zhao H, Wolt JD (2017) Risk associated with off-target plant genome editing and methods for its limitation. Emerg Topics Life Sci 1(2):231-240. https://doi.org/10.1042/ etls20170037

Zhenbin Y, Kankanhalli A, Ha S, Tayi GK (2020) What drives public agencies to participate in open government data initiatives? an innovation resource perspective. Inf Manag 57(3):103179. https://doi.org/10.1016/j.im.2019.103179

Zhu H, Li C, Gao C (2020) Applications of CRISPR-Cas in agriculture and plant biotechnology. Nat Rev Mol Cell Biol 21(11):661-677. https://doi.org/10.1038/s41580-02000288-9

Publisher's Note Springer Nature remains neutral with regard to jurisdictional claims in published maps and institutional affiliations. 